\title{
Monitoring the employment of graduates as an information resource for adjusting the work programs of disciplines
}

\author{
Tatiana Zainullina*, Igor Komarnitskiy, Liliya Karich, and Irina Kedrova \\ Don State Technical University, 344000, Rostov-on-Don, Russia
}

\begin{abstract}
The article studies analysing the employment of undergraduate students in the spheres of training "Tourism," "Service" and "Hospitality" as an integral part of the educational process for students in the field of tourism and hospitality. The main challenges faced by experience-based education were highlighted and ways of addressing them were outlined. In particular, the difficulties associated with organizing the employment of graduates were being examined, employment was being monitored to identify employers' preferences and students' expectations and, on that basis, curriculum and curriculum adjustments were being carried out.
\end{abstract}

\section{Introduction}

One of the important indicators characterizing the quality of bachelor's degree training is the demand of graduates in the labor market, which can be traced by analyzing their employment. The employment of graduates is given considerable attention, as evidenced by the inclusion of this indicator, along with such as educational activities, international activities, financial and analytical activities and infrastructure, in the monitoring system of Russia universities.

The employment of graduates is also influenced by the directed development of practical-oriented education - this is education, the main goal of which is the formation of practical work among students of professional competencies demanded by employers today, as well as the formation of an understanding of how the competencies obtained during training can be applied in practice. Therefore, when formulating curricula and developing curricula of educational disciplines, attention should be paid to the requirements of employers, as well as take into account the opinion of graduates who have already completed their studies

\section{Review of scientific sources}

The concept of problem-oriented and practice-oriented education is considered and studied by such authors as: Duch, B. J., Groh, S. E, Allen, D. E. (2001) [1], Grasha, A. F. (1996)

\footnotetext{
* Corresponding author: tat-zajnullina@yandex.ru
} 
[2], John R. Savery (2006) [3], Labaree, D. F. 2003 [4], Chang, J., Chalcraft, D. and Rieple, A. (2015) [5].

In studies, Professor Woods, D. R. (1996, 2005) [6.7] notes that graduates are more positive about their "technological skills" than about their knowledge of the subject.

Unlike "theory-based learning," practice-based learning requires a student to study and apply theory in a real working environment from the very beginning.

Problematic and practical approaches to learning have a long story of supporting learning based on experience. Psychological research and theory show that by giving students the opportunity to learn from their own experience in solving problems, they can study both content and thinking strategies. Problem-oriented learning (PBL) is a learning method in which students learn to facilitate problem solving. In PBL, student education focuses on a complex problem that does not have the only right answer. The theory of problem-oriented and practice-oriented education and training was developed by the authors: Barrows, H. S. (1986) [8], Savery, J. R., \& Duffy, T. M. (1995) [9], Albanese, M. A., and Mitchell, S. (1993) [10].

The problem of graduate employment is actively studied by Chinese scientists, in particular Tang, H (2020) [12] and 13. Zheng, J. Tang J. and Gao J. (2012) [13] review "quality of employment" indicators and develop indices for assessing this quality.

Russian scientists are also studying and developing indicators for monitoring the employment of graduates of universities. Ovchinkin, O. (2019) [14], 15. Volovskaya, N. M., Plyusnina, L. K., \& Rusina, A. V. (2014) [15].

\section{Methods of research}

The following research methods were used in the work: analysis of scientific sources, synthesis of scientific ideas, foreign experience, description of the concept of practicaloriented education and training, questionnaire of heads of employer enterprises.

In preparing this study, the authors developed a questionnaire for potential employers and graduate students in order to find out how they assess employment opportunities in the directions of training 43.03.01 "Service," 43.03.02 "Tourism" and 43.03.03 "Hotel Business" of the "Service and Tourism" faculty of the Don State Technical University and what stops employers when hiring young specialists and what expectations exist when employing graduates.

\section{Results and Discussion}

Issues related to the employment of undergraduate graduates are relevant for any profile. Service, tourism and the hospitality industry are no exception. Often, after 4 years of training (or 4.5 in absentee form), graduates face the problems of finding a job in a specialty, most often it is the lack of demand of employees without a certain experience, poor knowledge of modern information, professional and communication technologies necessary for productive work and simply inadequate perception of the modern state of development of a particular branch of the economy, including the level of wages.

As a rule, graduates of the full-time department are offered to fill out a questionnaire developed by specialists from the marketing research sector of the Practice, Employment and Enterprise Relations department. When designing the questionnaire, closed-form questions were used with the choice of one or more answers, which made it possible to process information in a short time. In terms of content, the questions were aimed both at identifying the identity of the respondent, and at identifying his opinions, wishes, preferences in the field of employment. 
Over the last two years of the questionnaire (2019-2020), graduates of directions of training, which are presented in Figure 1, outlined changes in the structure of preferences.

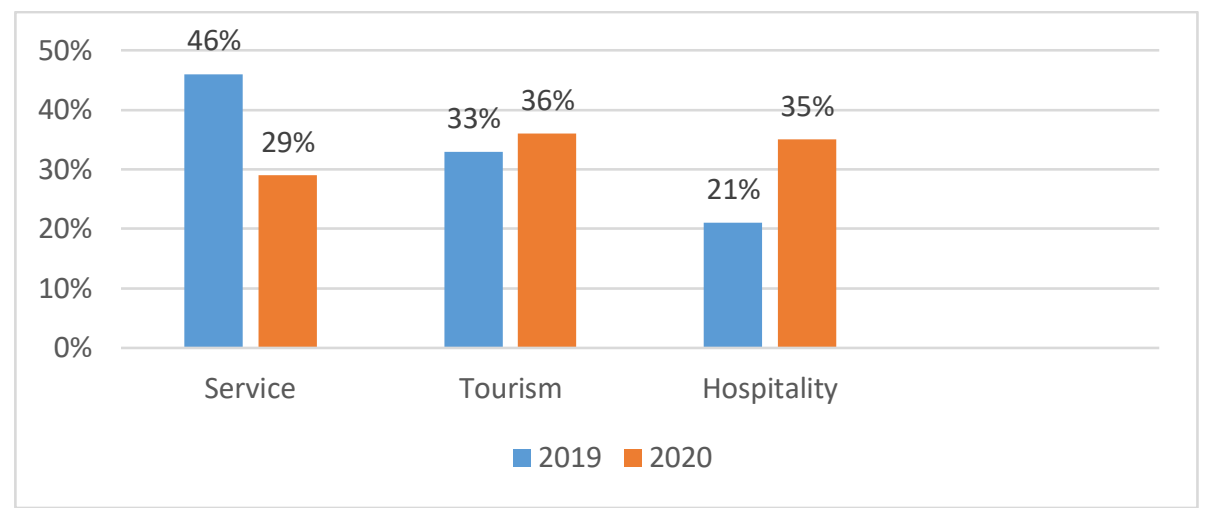

Fig. 1. Distribution of graduates who completed questionnaires by directions of training

Potential employers will be interested in the fact that some working graduates at the time of completion of their studies at DSTU have experience. The preferences of employers in this matter have undergone significant changes; in particular, a larger percentage of employers (38\% of respondents) began to give preference to employees with more than 1 year of service, as can be seen from figure 2 .

It should also be noticed that if in $20198 \%$ of employers did not attach importance to the experience, then in 2020 this number increased to $17 \%$. In our opinion, this is due to the increase in the turnover of personnel due to the pandemic and restrictions on movement, when employers are ready to take graduates without experience with probationary work or for types of work that do not require qualifications in a specialty, but with lower wages.

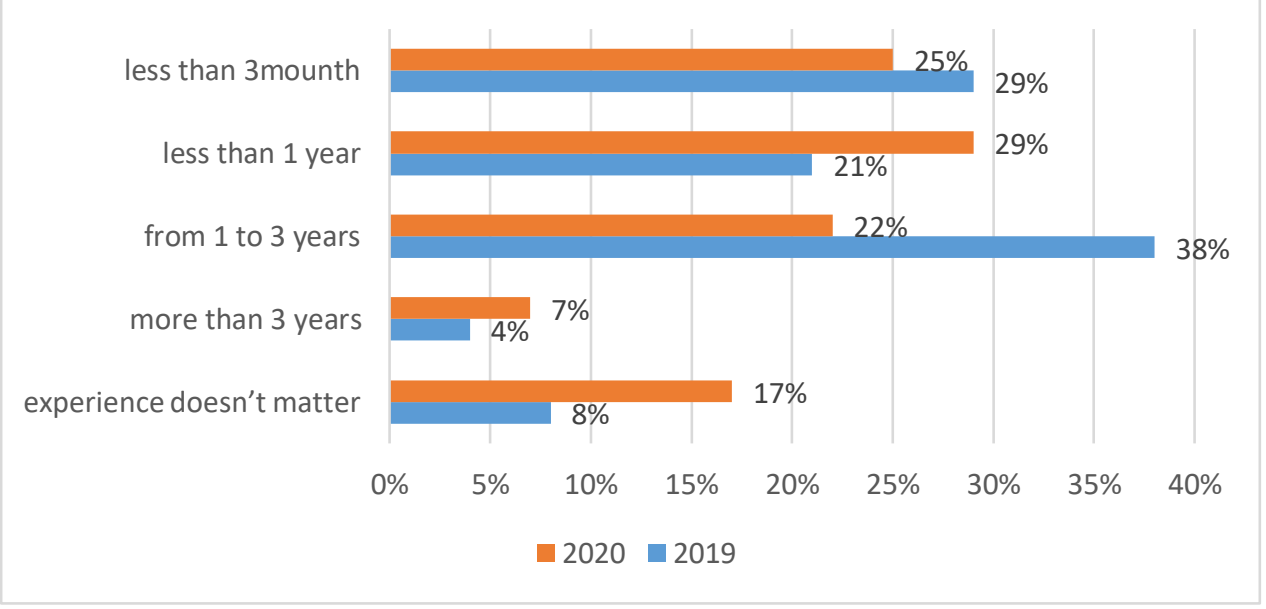

Fig. 2. Work experience of graduates working in the specialty

Some of the graduates surveyed already have a work experience of one to three years, which is associated with employment during the training period, including during practices (primarily industrial). At the same time, a small proportion of graduates with minimal seniority testify to the difficulties that accompany attempts to find work without any experience in the specialty.

In ranking the factors influencing the choice of place of work, graduates identified the following factors (several answer options were possible): 
- 1 place - money and benefits (50\%);

- 2nd place proximity to the house $(46 \%)$;

- 3rd place - career (35\%);

- -4 th place - the prestige of the company $(29 \%)$;

- 5 th place - acquisition of new experience and knowledge (25\%);

- 6th place - stability and reliability $(21 \%)$.

Compared to 2019, the rank of money and benefits increased in 2020. The current pandemic situation, proximity to home has come second, which has the same explanation, as daily transport spending becomes particularly palpable during a pandemic period. In addition, there is autonomy and responsibility, which indicates growing up and increasing consciousness in the choice of activities among young people. After that, follows a career, which confirms the unflagging ambition of young people, finally - the acquisition of new experience and knowledge, for some reason, the indicator of stability and reliability has become low, which most likely reflects the instability of the modern economic situation.

Thus, based on the results of the analysis, it can be concluded that the percentage of full-time graduates employed (41\%) of the study indicates that modern students begin to seek use of forces in the labor market, starting from the second year. This is a requirement of time, which is determined by the need for young people to search almost from the first years of study at a university due to the inability to precisely determine the choice of profession after school. Young people begin to try themselves in different fields of activity, not only in a direction close to the chosen direction of training at the university; this is indicated by the percentage of people employed outside the specialty $(16 \%)$. In addition to this reason, there is another, also determined by the features of our reality: often students choose those types of work not in the specialty that bring a good income, in order to earn money for education. The percentage of employees in the specialty is also quite high for full-time students - $25 \%$. This is a good indicator of the quality of education received; allowing students to find use forces in the sphere of activity chosen for education. Part of the unemployed graduates is slightly more than the employed $-59 \%$.

Requests for the initial level of wages increased compared to last year, which is justified by the economic situation in the country and the desire of young specialists to have not the minimum, but the average size of salaries at the start $(25,000$ rubles - 55\%), which is supported by the desire of graduates to reasonably put forward such requirements, as indicated by previous figures and indicators.

\section{Conclusion}

The following conclusions can be drawn from the study.

Practical-oriented education is the necessary basis for training personnel in the field of service, tourism and hospitality, since the personnel potential of this sphere directly affects the quality of service. The practical orientation throughout the entire period of theoretical training, combined with internships in tourist and hotel enterprises, will make it possible to train specialists for the requirements of employers.

The analysis of the survey data of heads of service, tourism and hospitality enterprises revealed weak links in the training of graduates.

The ranking of factors affecting the choice of place of work by graduates has changed, due to the pandemic and rising prices for significant goods and services (transport, rental of apartments, etc.) 


\section{References}

1. B.J. Duch, S.E. Groh, D.E. Allen, (Eds.), The power of problem-based learning. Sterling (VA: Stylus, University Delaware, 2001).

2. A.F. Grasha, Teaching with style: A practical guide to enhancing learning by understanding teaching and learning styles (Pittsburgh, Alliance Publishers, 1996).

3. R. John, Savery Overview of Problem-Based Learning: Definitions and Distinctions Article (2006).

4. D.F. Labaree, Educational Researcher 32 (4) 13-22. (2003).

5. J. Chang, D. Chalcraft, and A. Rieple, Practice Based Curriculum for Effective Entrepreneurship Education in HE. Practice Based Curriculum for Effective Entrepreneurship Education in HE. Research in Management Learning and Education (RMLE), Lima, Peru 21 - 25 Jun 2015 Eastern Academy of Management (2015).

6. D.R. Woods, Problem-based learning: Helping your students gain the most from PBL (1996).

7. D.R. Woods, Problem-based learning (McMaster University, Hamilton, 2005).

8. H.S. Barrows, Medical education 20 (6), 481-486 (1986).

9. J.R. Savery, T.M. Duffy, Educational technology 35 (5), 31-38 (1995).

10. M.A. Albanese, and S. Mitchell, Acad. Med. 68, 52-81 (1993).

11. E. Glazer, (Chapter 14) Attribution CC 3.0. Retrieved from https://textbookequity.org/Textbooks/Orey_Emerging_Perspectives_Learning.pdf (2010).

12. H. Tang, Advances in Social Science. Education and Humanities Research, 383, 296-300 (2020).

13. J. Zheng, J. Tang and J. Gao, AASRI Procedia 1 410-415 (2012).

14. O. Ovchinkin, International journal of emerging trends in engineering research 7 (12), 849-853 (2019).

15. N.M. Volovskaya, L.K. Plyusnina, A.V. Rusina, Theory and practice of social development 19, 23-27 (2014). 